Review

\title{
Function and Pathological Implications of Exon Junction Complex Factor Y14
}

\author{
Tzu-Wei Chuang ${ }^{\dagger}$, Kou-Ming Lee ${ }^{\dagger}$ and Woan-Yuh Tarn * \\ Institute of Biomedical Sciences, Academia Sinica, Taipei 115, Taiwan; \\ E-Mails: tzuwei@ibms.sinica.edu.tw (T.-W.C.); g39002007@ym.edu.tw (K.-M.L.) \\ $\dagger$ These authors contributed equally to this work. \\ * Author to whom correspondence should be addressed; E-Mail: wtarn@ibms.sinica.edu.tw; \\ Tel.: +886-2-2652-3052; Fax: +886-2-2782-9142.
}

Academic Editor: André P. Gerber

Received: 26 February 2015 / Accepted: 1 April 2015 / Published: 10 April 2015

\begin{abstract}
Eukaryotic mRNA biogenesis involves a series of interconnected steps, including nuclear pre-mRNA processing, mRNA export, and surveillance. The exon-junction complex (EJC) is deposited on newly spliced mRNAs and coordinates several downstream steps of mRNA biogenesis. The EJC core protein, Y14, functions with its partners in nonsense-mediated mRNA decay and translational enhancement. Y14 plays additional roles in mRNA metabolism, some of which are independent of the EJC, and it is also involved in other cellular processes. Genetic mutations or aberrant expression of Y14 results in physiological abnormality and may cause disease. Therefore, it is important to understand the various functions of Y14 and its physiological and pathological roles.
\end{abstract}

Keywords: exon-junction complex; nonsense-mediated mRNA decay; translation; pre-mRNA splicing; centrosome

\section{Introduction}

RNA processing is a critical step of eukaryotic gene expression and is tightly regulated to control and orchestrate a variety of biological processes. During transcription, nascent transcripts of RNA polymerase II undergo 5' capping, 3' cleavage, and polyadenylation as well as splicing, by which introns are removed, to become mature mRNAs. Throughout the maturation process, precursor mRNAs (pre-mRNAs) are 
decorated with various proteins to form a high-order messenger ribonucleoprotein (mRNP) complex. Mature mRNPs are exported to the cytoplasm where translation and mRNA turnover take place $[1,2]$.

During splicing, a specific set of proteins that constitute the exon-junction complex (EJC) is loaded onto spliced mRNA $[1,3]$. The EJC is involved in several mRNA maturation events, including splicing, mRNA export, nonsense-mediated mRNA decay (NMD), and translational control, and it serves as an important molecular determinant of the nuclear history of mRNA (i.e., influence of nuclear RNA processing events on the cytoplasmic fates of mRNAs) [4]. The tetrameric core of the EJC is composed of the Y14-Magoh heterodimer, eukaryotic initiation factor 4AIII (eIF4AIII), and metastatic lymph node 51 (MLN51, also known as Barentsz or CASC3). Deposition of the EJC core upstream of the spliced junction is mediated by the specific interaction between eIF4AIII and CWC22, a component of the spliceosome-activating PRP19 complex, during splicing [5,6]. In addition, several peripheral proteins join to form an outer shell of the EJC complex and participate in different steps of mRNA metabolism [7-9]. Among them, NXF1 acts as the primary mRNA export receptor, and the surveillance factors Upf3 and Upf2 function in NMD. NMD is an mRNA surveillance pathway that degrades aberrant mRNAs that contain a premature termination codon $[10,11]$. Upf3 and Upf2 recruit Upf1 to the EJC, which interacts with the upstream and halted ribosome on a premature termination codon and triggers degradation of the NMD-susceptible mRNA $[12,13]$. Otherwise, the EJC is removed from normal transcripts by the scanning ribosome during the pioneer round of translation [14].

Recent genome-wide analyses indicate that EJCs not only occupy the majority of exon junctions but also bind non-canonical sites in the coding sequences and the 5' and $3^{\prime}$ untranslated regions (UTRs) [15-17]. Interestingly, EJC-binding sites are often associated with the RNA motifs that resemble the binding sites for serine-arginine-rich splicing factors (SR proteins). Therefore, it is possible that SR proteins can influence EJC loading to the sites beyond exon junctions. EJCs and SR proteins multimerize to promote packaging and compaction of spliced mRNAs and subsequent mRNA biogenesis steps [17]. In addition, individual EJC components can also exert distinct and EJC-independent functions in various cellular processes [18-21]. Furthermore, some genetic diseases are associated with mutations in the genetic loci encoding the EJC components [22]. In this article, we focus on various functions of the EJC core protein Y14 and its potential role in disease pathogenesis.

\section{Y14 as an EJC Core Protein}

Y14 and its heterodimeric partner Magoh are conserved from Schizosaccharomyces pombe to human. Y14 contains an RNA-binding domain (RBD) in the central region. Magoh binds with high affinity to the RBD surface of Y14 and masks its RNA-binding surface [23,24]. Notably, the most $C$-terminal region of vertebrate and $S$. pombe Y14 proteins contains two consecutive arginine/serine (RS) dipeptides. RS dipeptide phosphorylation can modulate the association of Y14 with other mRNA biogenesis factors and may govern its cellular functions [25]. For example, phosphorylated Y14 does not interact with the NMD factors, suggesting that phosphorylation of Y14 remodels the NMD complex during initial rounds of translation or prevents nonspecific NMD complex formation in the nucleus $[25,26]$. Moreover, the arginine residues adjacent to the RS dipeptides can be methylated, which is antagonized by RS dipeptide phosphorylation. Thus, the interplay between phosphorylation and methylation may modulate the various functions of Y14 [25]. 
In the EJC core, Y14 does not directly bind mRNA; instead eIF4AIII confers the activity for the sequence-independent interaction with exon junctions. In the presence of ATP, the two RecA domains of eIF4AIII form a large RNA clamp that interacts with the phosphate-ribose backbone of six nucleotides [27,28]. Y14-Magoh directly interacts with eIF4AIII and inhibits its ATPase activity to ensure the stable association of the EJC core with RNA [29]. The EJC core remains associated with the mRNA after its export to the cytoplasm [8]. Y14-Magoh is likely removed upon translation and subsequently recycled into the nucleus [14].

\section{Subcellular Localization of Y14}

Y14 localizes mainly in the nucleoplasm and continuously shuttles between the nucleus and the cytoplasm. Y14 may be imported into the nucleus alone or as a heterodimer with Magoh [30,31]. In the nucleus, Y14 as well as other EJC core factors, are concentrated in perispeckles, which surround splicing factor-enriched speckles [32]. The EJC core may assemble onto transcripts undergoing splicing in perispeckles [32]. In the cytoplasm, neither Y14-Magoh nor eIF4AIII is enriched in particular RNA granules, stress granules, or processing bodies (P-bodies) [21,33]. P-bodies are cytoplasmic foci containing translationally silenced mRNAs that are subject to degradation or reenter the translating pool [34]. Evidence indicates that some of the NMD factors cycle through P-bodies and accumulate in P-bodies when mRNA degradation is disrupted [35,36]. Localization of Y14 in cytoplasmic P-bodies is minimal but can be marginally enhanced by blocking disassembly of the NMD complex [35]. However, depletion of Y14 impedes P-body formation or accumulation, suggesting that Y14 plays an essential role in P-body biogenesis [37]. More interestingly, overexpression of a phosphomimetic Y14 mutant induces P-body formation [37]. Perhaps blockade of Y14 dephosphorylation prevents recycling of mRNA-degradation factors and in turn causes their accumulation in P-bodies. Nevertheless, this observation reiterates the importance of the phosphorylation/dephosphorylation cycle of Y14 in remodeling of post-splicing mRNPs and perhaps in determining mRNA fate.

\section{Canonical Functions of Y14 in mRNA Metabolism}

\subsection{Y14 Plays an Important Role in NMD}

Tethering of Y14 to the 3' UTR of NMD reporter mRNAs elicits their degradation [10,38-40]. Accordingly, depletion of Y14 impairs the degradation of premature termination codon-containing transcripts, suggesting a critical role of Y14 in NMD [38,39]. Y14-Magoh directly interacts with Upf3 to form an NMD-activating complex [11,41]. An early study indicated that Upf2 is required for tethered Y14-mediated NMD [38]. However, distinct branches of the NMD pathway have been proposed based on their different cofactor requirements and substrate features [39,41-43]. As compared with RNPS1-induced NMD, the Y14-Magoh-mediated pathway appears to depend to a lesser extent on Upf2, suggesting that Y14 has differential contributions across different NMD pathways [39,43]. Moreover, Y14 is also reported to be involved in fail-safe NMD, which requires the long 3' UTR and is generally EJC-independent [44]; whether the binding of Y14 to the 3' UTR and/or translational enhancement by Y14 (see below) contribute to the fail-safe NMD remains to be determined. Therefore, individual EJC factors may function via interactions with somewhat different sets of NMD factors to differentially 
determine the fate of individual mRNAs or act in response to particular cellular signaling pathways or environmental cues.

\subsection{Y14 Enhances Translation}

It has been long believed that splicing enhances mRNA expression, which occurs in part through the action of the EJC [45]. The EJC has a particular function in the cap-binding complex (CBC)-mediated pioneer round of translation, by which it enhances NMD [14,46]. eIF4AIII directly interacts with the CBC-dependent translation initiation factor (CTIF), which recruits the translation initiation factor eIF3 complex to facilitate the loading of the 40S ribosomal subunit onto the 5' end of an mRNA [20,47]. Y14-Magoh interacts with the partner of Y14-Magoh (PYM) protein, a factor that stimulates translation by bridging the EJC and 48S pre-initiation complex [48]. Tethering of either Y14 or Magoh to an intron-containing luciferase transcript results in higher translational yield [49]. Depletion of Y14 inhibits splicing-dependent translational activation, reinforcing its essential role in translation enhancement [50]. Similar effects have been detected for eIF4AIII. Moreover, overexpression of MLN51 can enhance productive translation [51]. However, an analysis using luciferase reporters containing different internal ribosome entry sites indicates that Y14 may function in an earlier step of translation, whereas eIF4AIII activates translation after $80 \mathrm{~S}$ ribosome complex formation [50]. Perhaps EJC factors act in concert to promote the pioneer round of translation but modulate productive translation via different mechanisms and variably regulate specific genes. The finding that Y14 binds the mRNA 5' cap suggests an additional possibility that it might modulate translation by interacting with the cap [37].

\section{Additional Functions of Y14 in Various Biological Processes}

\subsection{Y14 Promotes PRMT5 Activity}

We have reported an unprecedented role for Y14 in promoting the activity of the methylosome [52]. The Y14-Magoh heterodimer specifically interacts with the cytoplasmic methylosome, which is composed of the arginine methyltransferase PRMT5, chaperon protein pICln, and WD repeat-containing protein MEP50/WD45 [53-55]. PRMT5 can symmetrically dimethylate arginine residues and target a wide range of substrates, including the Sm proteins of the spliceosomal small nuclear ribonucleoproteins (snRNPs) [56,57]. During snRNP biogenesis, the cytoplasmic survival of motor neuron (SMN) complex facilitates the assembly of methylated Sm proteins onto the snRNA. Y14 enhances PRMT5-mediated methylation of Sm proteins in vitro [52]. Overexpression of Y14 enhances Sm protein methylation and assembly by inducing the formation of a larger methylosome complex containing multimerized PRMT5, which confers higher methylation activity, and the SMN complex [52]. The finding that Y14 also participates in snRNP biogenesis may indicate that Y14 coordinates snRNP production with pre-mRNA splicing and maturation, and perhaps it may fine-tune mRNA expression.

\subsection{Y14 Inhibits mRNA Decapping}

Y14-Magoh, but not eIF4AIII or MLN51, specifically associates with the mRNA decapping complex and mRNA degradation factors, suggesting a specific and EJC-independent role for Y14 in modulating mRNA degradation [37]. Indeed, Y14 directly interacts with Dcp2 and inhibits the decapping activity of 
Dcp2 in vitro. Overexpression of Y14 prevents degradation of reporter mRNAs bearing an AU-rich destabilizing element [37]. It remains unclear, however, whether the binding of Y14 to the 5' cap is a prerequisite for its role in preventing mRNA decay. Notably, in regard to cap binding and mRNA stabilization, Y14 acts analogously to the testis-specific decapping regulator VCX-A (variably charged, $\mathrm{X}$ chromosome mRNA on CRI-S232A). VCX-A may function in brain development, and its deletion is associated with mental retardation [58,59]. Interestingly, Y14 has been detected in both the axons and dendrites of the primary cortical neurons [60]. Gain-of-function or overexpression of Y14 in the brain results in abnormal behavior [60,61]. Thus, it is of great interest to elucidate how Y14 may regulate mRNA surveillance or decay in EJC-dependent or -independent pathways in neurons.

\subsection{Y14 Regulates Alternative Splicing}

Y14 as well as several other EJC factors can directly regulate alternative splicing. This is not completely unexpected because the EJC core components are likely loaded onto pre-mRNA prior to completion of splicing and are indeed detected in late spliceosomal complexes [62,63]. Evidence indicates that EJC factors particularly regulate alternative splicing of apoptotic factors, which generate isoforms with opposing roles in apoptosis [9]. Depletion of Y14 enhances the expression of the proapoptotic isoforms of Bcl-x, Bim, and Mcl1, and accordingly promotes apoptosis. Y14 was also identified through a loss-of-function screen of genes involved in cell proliferation and apoptosis in a human mesothelioma cell line [64]. Therefore, Y14 may act as an anti-apoptotic factor and regulate cell viability. Notably, Magoh and certain other EJC factors specifically regulate alternative splicing of RAS/MAPK signaling factors in Drosophila [65,66]. However, whether and how EJC-mediated splicing regulation is functionally linked to NMD still warrants further investigation.

\subsection{The Role of Y14 in Cell Cycle Control}

Depletion of NMD factors impedes cell proliferation and causes cell cycle arrest [67-69]. Indeed, some of the NMD factors regulate the expression of gene sets associated with particular biological processes, including cell cycle progression [69]. Knockdown of individual EJC core factors results in mitotic spindle defects and an increase in DNA damage foci [18]. Notably, a mutagenesis screen determined the specific role of Magoh in mouse neural stem cell division as well as its contribution to efficient centrosome maturation in neural progenitor cells [18]. Depletion of Y14 results in G2/M arrest followed by apoptosis, but its overexpression also causes cell death [67,70]. It is possible that Y14-Magoh, in conjunction with other mRNA surveillance factors, particularly modulates the expression of cell cycle-related transcripts via splicing-coupled NMD, and thereby regulates cell viability. Coincidently, most recent reports have indicated that since a set of NMD targets encodes cell cycle inhibitory and pro-apoptotic factors, attenuation of NMD sensitizes cancer cells to chemotherapeutic agent-induced apoptosis [71,72]. Nevertheless, the observation that both Y14 and Magoh physically localize to the centrosome suggests their potential role in centrosome regulation [67]. The centrosome is essential not only for mitotic spindle formation but also for G2/M checkpoint control and DNA damage signaling [73]. Therefore, Y14 may be essential for mitotic progression or act as a regulator of this process. 


\section{The Physiological and Pathological Roles of Y14}

\subsection{Y14 in the Thrombocytopenia-Absent Radius Syndrome}

Y14 has been implicated in the thrombocytopenia-absent radius (TAR) Syndrome [74,75]. TAR results from deletion of one RBM8A allele that encodes Y14 on chromosome 1q21.1 in conjunction with deleterious regulatory single-nucleotide polymorphisms in the other allele, and it is characterized by both thrombocytopenia and absent radii with the presence of thumbs [74,75]. In particular, TAR patients have low numbers of platelet precursors in the bone marrow. This is reminiscent of a previous study showing that hematopoietic-specific depletion of Upf2 resulted in depletion of hematopoietic stem cells [76]. Thus, Y14 as well as some of the NMD factors may particularly regulate the expression of genes involved in the proliferation of hematopoietic cells. Moreover, deletions of the 1q21.1 proximal region are associated with a spectrum of developmental delays, particularly in the brain [77], suggesting that $R B M 8 A$ and/or adjacent genes may play roles in brain development.

\subsection{Y14 in Neuronal Development and Function}

The finding that Y14-deficient TAR patients exhibit mental retardation and Y14 is expressed in neurons suggests a role for Y14 in neuronal development and function [18,77,78]. Additionally, copy number variations of several EJC/NMD factors including Y14 also lead to neurological diseases [61]. Overexpression of Y14 in the dentate gyrus of mice results in abnormal emotional behavior [60]. Accordingly, Y14 binds the mRNA transcripts that impact synaptic plasticity and behavior, and its overexpression affects miniature excitatory postsynaptic currents in cultured neurons, suggesting increased synaptic contacts [60]. A mutagenesis screen revealed that Magoh haploinsufficiency causes microcephaly owing to depletion of intermediate neural progenitors and neuronal apoptosis [18]. Magoh is involved in neural stem cell division and controls the expression level of the microcephaly-associated protein Lis1 during neurogenesis [18]. It is noteworthy that MagohB, the Magoh analog, may function redundantly with Magoh, but their expression may be differentially regulated [79]. Moreover, microdeletions of chromosome regions encompassing $R B M 8 A$ are associated with mental retardation and microcephaly [77,80], emphasizing the role of Y14-Magoh in neuronal development. The observation that Y14 or Magoh depletion disrupts mitotic spindle orientation and integrity, chromosome number, and genomic stability may explain their possible role in neurogenesis during brain development [18]. Perhaps the potential roles of Y14 and Magoh in centrosomal function also contribute to proper neuronal cell division during development.

\subsection{Additional Pathological Potential of Y14}

Autoantibodies against Sm proteins are prevalent in patients with systemic lupus erythematosus. The anti-Sm autoimmune response involves multiple epitopes of Sm proteins, including symmetrically dimethylated arginines in the arginine-glycine repeats of Sm D1 and D3 [81,82]. Differential methylation of Sm proteins may account for the observed variations in autoantibody expression and affinity $[82,83]$. Therefore, we speculate that Y14 may modify immune function in TAR patients via PRMT5-mediated 
protein methylation. Furthermore, Y14 inhibits mRNA decapping and modulates alternative splicing, which conceivably would impact the transcriptome profile and have physiological consequences.

\section{Conclusions and Prospective}

Y14 is engaged in several steps of mRNA biogenesis and translation and may also have specialized roles in other cellular processes such as signaling and centrosome control [19,21,35]. Questions listed below remain to be answered by future investigation.

Accumulating evidence indicates that various NMD targeting features exist, such as an atypically long 3' UTR and upstream open reading frame [22]. Notably, EJCs also bind to UTRs, i.e., non-canonical binding sites for the EJC $[15,16,20]$. Therefore, it will be interesting to know whether those non-canonical NMD events exhibit different dependency on the EJC complex or involve variable EJC components. Moreover, a recent report showed that eIF4AIII binds to the 5' UTR of transcripts and facilitates the translation of those transcripts containing structured elements [20]. Perhaps Y14 also has preferential targets and modulates their expression via diverse mechanisms.

Recent studies have begun to reveal the effect of cellular signaling pathways on NMD. Under nutrient-sufficient conditions, the mTOR-activated kinase S6K1 is recruited to the EJC bound to newly synthesized mRNAs to promote their pioneer round of translation [84]. In stressed cells, NMD is generally inhibited, but selective translation may be maintained for cellular adaptation and to ensure cell survival $[85,86]$. Questions remain as to whether any of the EJC components are modified and how the activity of the EJC is modulated by various cellular stimuli. Our previous report showed that phosphorylation/dephosphorylation of Y14 modulates its interaction with the NMD and translation factors [25]. Thus, Y14 may be a target of cellular signaling kinases. Nevertheless, this hypothesis as well as the specific function of Y14 in response to cellular cues remains to be tested.

EJC and NMD factors are particularly engaged in the control of cell cycle progression and maintenance of genome stability $[22,76]$. As intriguing as the centrosomal localization of Y14-Magoh, several NMD effectors, namely suppressors with morphogenetic defects in genitalia (SMG) proteins, are enriched at telomeres [87]. Notably, centrosomal components also include RNA, which has been proposed to interact with spindles in a structural role or to determine asymmetric centrosome localization during stem cell division [88]. It would be of interest to know whether Y14 and Magoh function as mitotic regulators via association with centrosomal RNAs and/or participate in local mRNA translation at the centrosome.

Finally, the implication of EJC and NMD factors in neurodevelopmental disorders is also noteworthy $[22,89,90]$. NMD is coupled to alternative splicing and eliminates aberrant splicing products to ensure proper gene expression. The abundance of alternative splicing events that take place in neuronal cells may render them sensitive to NMD. Nevertheless, the specific role of Y14 in neuronal mRNA expression and perhaps in neuronal stem cell division warrants future investigation.

\section{Acknowledgments}

We thank Shin-Wu Liu for critical reading of the manuscript. This work was supported by Grant MOST-102-2311-B-001-025-MY3 of the Ministry of Science and Technology of Taiwan. 


\section{Author Contributions}

Tzu-Wei Chuang, Kou-Ming Lee and Woan-Yuh Tarn wrote the manuscript.

\section{Conflicts of Interest}

The authors declare no conflicts of interest.

\section{References}

1. Muller-McNicoll, M.; Neugebauer, K.M. How cells get the message: Dynamic assembly and function of mRNA-protein complexes. Nat. Rev. Genet. 2013, 14, 275-287.

2. Popp, M.W.; Maquat, L.E. The Dharma of nonsense-mediated mRNA decay in mammalian cells. Mol. Cells 2014, 37, 1-8.

3. Le Hir, H.; Izaurralde, E.; Maquat, L.E.; Moore, M.J. The spliceosome deposits multiple proteins 20-24 nucleotides upstream of mRNA exon-exon junctions. EMBO J. 2000, 19, 6860-6869.

4. Bono, F.; Gehring, N. Assembly, disassembly and recycling: The dynamics of exon junction complexes. RNA Biol. 2011, 8, 24-29.

5. Alexandrov, A.; Colognori, D.; Shu, M.D.; Steitz, J.A. Human spliceosomal protein CWC22 plays a role in coupling splicing to exon junction complex deposition and nonsense-mediated decay. Proc. Natl. Acad. Sci. USA 2012, 109, 21313-21318.

6. Barbosa, I.; Haque, N.; Fiorini, F.; Barrandon, C.; Tomasetto, C.; Blanchette, M.; le Hir, H. Human CWC22 escorts the helicase EIF4AIII to spliceosomes and promotes exon junction complex assembly. Nat. Struct. Mol. Biol. 2012, 19, 983-990.

7. Tange, T.O.; Nott, A.; Moore, M.J. The ever-increasing complexities of the exon junction complex. Curr. Opin. Cell Biol. 2004, 16, 279-284.

8. Tange, T.O.; Shibuya, T.; Jurica, M.S.; Moore, M.J. Biochemical analysis of the EJC reveals two new factors and a stable tetrameric protein core. RNA 2005, 11, 1869-1883.

9. Michelle, L.; Cloutier, A.; Toutant, J.; Shkreta, L.; Thibault, P.; Durand, M.; Garneau, D.; Gendron, D.; Lapointe, E.; Couture, S.; et al. Proteins associated with the exon junction complex also control the alternative splicing of apoptotic regulators. Mol. Cell. Biol. 2012, 32, 954-967.

10. Lykke-Andersen, J.; Shu, M.D.; Steitz, J.A. Human Upf proteins target an mRNA for nonsense-mediated decay when bound downstream of a termination codon. Cell 2000, 103, $1121-1131$.

11. Kim, V.N.; Kataoka, N.; Dreyfuss, G. Role of the nonsense-mediated decay factor hUpf3 in the splicing-dependent exon-exon junction complex. Science 2001, 293, 1832-1836.

12. Schoenberg, D.R.; Maquat, L.E. Regulation of cytoplasmic mRNA decay. Nat. Rev. Genet. 2012, 13, 246-259.

13. Schweingruber, C.; Rufener, S.C.; Zund, D.; Yamashita, A.; Muhlemann, O. Nonsense-mediated mRNA decay-Mechanisms of substrate mRNA recognition and degradation in mammalian cells. Biochim. Biophys. Acta 2013, 1829, 612-623.

14. Dostie, J.; Dreyfuss, G. Translation is required to remove Y14 from mRNAs in the cytoplasm. Curr. Biol. 2002, 12, 1060-1067. 
15. Muhlemann, O. Intimate liaison with SR proteins brings exon junction complexes to unexpected places. Nat. Struct. Mol. Biol. 2012, 19, 1209-1211.

16. Sauliere, J.; Murigneux, V.; Wang, Z.; Marquenet, E.; Barbosa, I.; le Tonqueze, O.; Audic, Y.; Paillard, L.; Roest Crollius, H.; le Hir, H.; et al. Clip-seq of EIF4AIII reveals transcriptome-wide mapping of the human exon junction complex. Nat. Struct. Mol. Biol. 2012, 19, 1124-1131.

17. Singh, G.; Kucukural, A.; Cenik, C.; Leszyk, J.D.; Shaffer, S.A.; Weng, Z.; Moore, M.J. The cellular EJC interactome reveals higher-order mRNP structure and an EJC-SR protein nexus. Cell 2012, 151, 750-764.

18. Silver, D.L.; Watkins-Chow, D.E.; Schreck, K.C.; Pierfelice, T.J.; Larson, D.M.; Burnetti, A.J.; Liaw, H.J.; Myung, K.; Walsh, C.A.; Gaiano, N.; et al. The exon junction complex component Magoh controls brain size by regulating neural stem cell division. Nat. Neurosci. 2010, 13, 551-558.

19. Togi, S.; Shiga, K.; Muromoto, R.; Kato, M.; Souma, Y.; Sekine, Y.; Kon, S.; Oritani, K.; Matsuda, T. Y14 positively regulates TNF-alpha-induced NF-kappaB transcriptional activity via interacting RIP1 and tradd beyond an exon junction complex protein. J. Immunol. 2013, 191, 1436-1444.

20. Choe, J.; Ryu, I.; Park, O.H.; Park, J.; Cho, H.; Yoo, J.S.; Chi, S.W.; Kim, M.K.; Song, H.K.; Kim, Y.K.; et al. EIF4AIII enhances translation of nuclear cap-binding complex-bound mRNAs by promoting disruption of secondary structures in 5' UTR. Proc. Natl. Acad. Sci. USA 2014, 111, E4577-E4586.

21. Cougot, N.; Daguenet, E.; Baguet, A.; Cavalier, A.; Thomas, D.; Bellaud, P.; Fautrel, A.; Godey, F.; Bertrand, E.; Tomasetto, C.; et al. Overexpression of MLN51 triggers p-body disassembly and formation of a new type of RNA granules. J. Cell Sci. 2014, 127, 4692-4701.

22. Nguyen, L.S.; Wilkinson, M.F.; Gecz, J. Nonsense-mediated mRNA decay: Inter-individual variability and human disease. Neurosci. Biobehav. Rev. 2014, 46, 175-186.

23. Fribourg, S.; Gatfield, D.; Izaurralde, E.; Conti, E. A novel mode of RBD-protein recognition in the Y14-mago complex. Nat. Struct. Biol. 2003, 10, 433-439.

24. Lau, C.K.; Diem, M.D.; Dreyfuss, G.; van Duyne, G.D. Structure of the Y14-Magoh core of the exon junction complex. Curr. Biol. 2003, 13, 933-941.

25. Hsu Ia, W.; Hsu, M.; Li, C.; Chuang, T.W.; Lin, R.I.; Tarn, W.Y. Phosphorylation of Y14 modulates its interaction with proteins involved in mRNA metabolism and influences its methylation. J. Biol. Chem. 2005, 280, 34507-34512.

26. Ishigaki, Y.; Nakamura, Y.; Tatsuno, T.; Ma, S.; Tomosugi, N. Phosphorylation status of human RNA-binding protein 8A in cells and its inhibitory regulation by Magoh. Exp. Biol. Med. 2014, doi:10.1177/1535370214556945.

27. Andersen, C.B.; Ballut, L.; Johansen, J.S.; Chamieh, H.; Nielsen, K.H.; Oliveira, C.L.; Pedersen, J.S.; Seraphin, B.; le Hir, H.; Andersen, G.R.; et al. Structure of the exon junction core complex with a trapped dead-box ATPase bound to RNA. Science 2006, 313, 1968-1972.

28. Bono, F.; Ebert, J.; Lorentzen, E.; Conti, E. The crystal structure of the exon junction complex reveals how it maintains a stable grip on mRNA. Cell 2006, 126, 713-725. 
29. Ballut, L.; Marchadier, B.; Baguet, A.; Tomasetto, C.; Seraphin, B.; le Hir, H. The exon junction core complex is locked onto RNA by inhibition of EIF4AIII ATPase activity. Nat. Struct. Mol. Biol. 2005, 12, 861-869.

30. Kataoka, N.; Diem, M.D.; Yoshida, M.; Hatai, C.; Dobashi, I.; Dreyfuss, G.; Hagiwara, M.; Ohno, M. Specific Y14 domains mediate its nucleo-cytoplasmic shuttling and association with spliced mRNA. Sci. Rep. 2011, doi:10.1038/srep00092.

31. Mingot, J.M.; Kostka, S.; Kraft, R.; Hartmann, E.; Gorlich, D. Importin 13: A novel mediator of nuclear import and export. EMBO J. 2001, 20, 3685-3694.

32. Daguenet, E.; Baguet, A.; Degot, S.; Schmidt, U.; Alpy, F.; Wendling, C.; Spiegelhalter, C.; Kessler, P.; Rio, M.C.; le Hir, H.; et al. Perispeckles are major assembly sites for the exon junction core complex. Mol. Biol. Cell 2012, 23, 1765-1782.

33. Baguet, A.; Degot, S.; Cougot, N.; Bertrand, E.; Chenard, M.P.; Wendling, C.; Kessler, P.; le Hir, H.; Rio, M.C.; Tomasetto, C.; et al. The exon-junction-complex-component metastatic lymph node 51 functions in stress-granule assembly. J. Cell Sci. 2007, 120, 2774-2784.

34. Decker, C.J.; Parker, R. P-bodies and stress granules: Possible roles in the control of translation and mRNA degradation. Cold Spring Harb. Perspect. Biol. 2012, doi:10.1101/cshperspect.a012286.

35. Franks, T.M.; Singh, G.; Lykke-Andersen, J. Upf1 ATPase-dependent mRNP disassembly is required for completion of nonsense-mediated mRNA decay. Cell 2010, 143, 938-950.

36. Durand, S.; Cougot, N.; Mahuteau-Betzer, F.; Nguyen, C.H.; Grierson, D.S.; Bertrand, E.; Tazi, J.; Lejeune, F. Inhibition of nonsense-mediated mRNA decay (NMD) by a new chemical molecule reveals the dynamic of NMD factors in p-bodies. J. Cell Biol. 2007, 178, 1145-1160.

37. Chuang, T.W.; Chang, W.L.; Lee, K.M.; Tarn, W.Y. The RNA-binding protein Y14 inhibits mRNA decapping and modulates processing body formation. Mol. Biol. Cell 2013, 24, 1-13.

38. Gehring, N.H.; Neu-Yilik, G.; Schell, T.; Hentze, M.W.; Kulozik, A.E. Y14 and hUpf3b form an NMD-activating complex. Mol. Cell 2003, 11, 939-949.

39. Gehring, N.H.; Kunz, J.B.; Neu-Yilik, G.; Breit, S.; Viegas, M.H.; Hentze, M.W.; Kulozik, A.E. Exon-junction complex components specify distinct routes of nonsense-mediated mRNA decay with differential cofactor requirements. Mol. Cell 2005, 20, 65-75.

40. Palacios, I.M.; Gatfield, D.; St. Johnston, D.; Izaurralde, E. An EIF4AIII-containing complex required for mRNA localization and nonsense-mediated mRNA decay. Nature 2004, 427, 753-757.

41. Chan, W.K.; Huang, L.; Gudikote, J.P.; Chang, Y.F.; Imam, J.S.; MacLean, J.A., 2nd; Wilkinson, M.F. An alternative branch of the nonsense-mediated decay pathway. EMBO J. 2007, 26, 1820-1830.

42. Chan, W.K.; Bhalla, A.D.; le Hir, H.; Nguyen, L.S.; Huang, L.; Gecz, J.; Wilkinson, M.F. A Upf3-mediated regulatory switch that maintains RNA surveillance. Nat. Struct. Mol. Biol. 2009, $16,747-753$.

43. Metze, S.; Herzog, V.A.; Ruepp, M.D.; Muhlemann, O. Comparison of EJC-enhanced and EJC-independent NMD in human cells reveals two partially redundant degradation pathways. RNA 2013, 19, 1432-1448.

44. Matsuda, D.; Hosoda, N.; Kim, Y.K.; Maquat, L.E. Failsafe nonsense-mediated mRNA decay does not detectably target EIF4E-bound mRNA. Nat. Struct. Mol. Biol. 2007, 14, 974-979.

45. Wiegand, H.L.; Lu, S.; Cullen, B.R. Exon junction complexes mediate the enhancing effect of splicing on mRNA expression. Proc. Natl. Acad. Sci. USA 2003, 100, 11327-11332. 
46. Maquat, L.E.; Tarn, W.Y.; Isken, O. The pioneer round of translation: Features and functions. Cell 2010, 142, 368-374.

47. Kim, K.M.; Cho, H.; Choi, K.; Kim, J.; Kim, B.W.; Ko, Y.G.; Jang, S.K.; Kim, Y.K. A new MIF4G domain-containing protein, CTIF, directs nuclear cap-binding protein CBP80/20-dependent translation. Genes Dev. 2009, 23, 2033-2045.

48. Diem, M.D.; Chan, C.C.; Younis, I.; Dreyfuss, G. PYM binds the cytoplasmic exon-junction complex and ribosomes to enhance translation of spliced mRNAs. Nat. Struct. Mol. Biol. 2007, 14, $1173-1179$.

49. Nott, A.; le Hir, H.; Moore, M.J. Splicing enhances translation in mammalian cells: An additional function of the exon junction complex. Genes Dev. 2004, 18, 210-222.

50. Lee, H.C.; Choe, J.; Chi, S.G.; Kim, Y.K. Exon junction complex enhances translation of spliced mRNAs at multiple steps. Biochem. Biophys. Res. Commun. 2009, 384, 334-340.

51. Chazal, P.E.; Daguenet, E.; Wendling, C.; Ulryck, N.; Tomasetto, C.; Sargueil, B.; le Hir, H. EJC core component MLN51 interacts with EIF3 and activates translation. Proc. Natl. Acad. Sci. USA 2013, 110, 5903-5908.

52. Chuang, T.W.; Peng, P.J.; Tarn, W.Y. The exon junction complex component Y14 modulates the activity of the methylosome in biogenesis of spliceosomal small nuclear ribonucleoproteins. J. Biol. Chem. 2011, 286, 8722-8728.

53. Friesen, W.J.; Paushkin, S.; Wyce, A.; Massenet, S.; Pesiridis, G.S.; van Duyne, G.; Rappsilber, J.; Mann, M.; Dreyfuss, G. The methylosome, a 20S complex containing JBP1 and pICln, produces dimethylarginine-modified Sm proteins. Mol. Cell. Biol. 2001, 21, 8289-8300.

54. Meister, G.; Eggert, C.; Buhler, D.; Brahms, H.; Kambach, C.; Fischer, U. Methylation of Sm proteins by a complex containing PRMT5 and the putative U snRNP assembly factor pICln. Curr. Biol. 2001, 11, 1990-1994.

55. Friesen, W.J.; Wyce, A.; Paushkin, S.; Abel, L.; Rappsilber, J.; Mann, M.; Dreyfuss, G. A novel WD repeat protein component of the methylosome binds Sm proteins. J. Biol. Chem. 2002, 277, 8243-8247.

56. Meister, G.; Fischer, U. Assisted RNP assembly: SMN and PRMT5 complexes cooperate in the formation of spliceosomal UsnRNPs. EMBO J. 2002, 21, 5853-5863.

57. Chari, A.; Golas, M.M.; Klingenhager, M.; Neuenkirchen, N.; Sander, B.; Englbrecht, C.; Sickmann, A.; Stark, H.; Fischer, U. An assembly chaperone collaborates with the SMN complex to generate spliceosomal snRNPs. Cell 2008, 135, 497-509.

58. Jiao, X.; Wang, Z.; Kiledjian, M. Identification of an mRNA-decapping regulator implicated in X-linked mental retardation. Mol. Cell 2006, 24, 713-722.

59. Fukami, M.; Kirsch, S.; Schiller, S.; Richter, A.; Benes, V.; Franco, B.; Muroya, K.; Rao, E.; Merker, S.; Niesler, B.; et al. A member of a gene family on XP22.3, VCX-A, is deleted in patients with X-linked nonspecific mental retardation. Am. J. Hum. Genet. 2000, 67, 563-573.

60. Alachkar, A.; Jiang, D.; Harrison, M.; Zhou, Y.; Chen, G.; Mao, Y. An EJC factor RBM8A regulates anxiety behaviors. Curr. Mol. Med. 2013, 13, 887-899.

61. Nguyen, L.S.; Kim, H.G.; Rosenfeld, J.A.; Shen, Y.; Gusella, J.F.; Lacassie, Y.; Layman, L.C.; Shaffer, L.G.; Gecz, J. Contribution of copy number variants involving nonsense-mediated mRNA decay pathway genes to neuro-developmental disorders. Hum. Mol. Genet. 2013, 22, 1816-1825. 
62. Merz, C.; Urlaub, H.; Will, C.L.; Luhrmann, R. Protein composition of human mRNPs spliced in vitro and differential requirements for mRNP protein recruitment. RNA 2007, 13, 116-128.

63. Gehring, N.H.; Lamprinaki, S.; Hentze, M.W.; Kulozik, A.E. The hierarchy of exon-junction complex assembly by the spliceosome explains key features of mammalian nonsense-mediated mRNA decay. PLoS Biol. 2009, 7, e1000120.

64. Sudo, H.; Tsuji, A.B.; Sugyo, A.; Kohda, M.; Sogawa, C.; Yoshida, C.; Harada, Y.N.; Hino, O.; Saga, T. Knockdown of COPA, identified by loss-of-function screen, induces apoptosis and suppresses tumor growth in mesothelioma mouse model. Genomics 2010, 95, 210-216.

65. Ashton-Beaucage, D.; Udell, C.M.; Lavoie, H.; Baril, C.; Lefrancois, M.; Chagnon, P.; Gendron, P.; Caron-Lizotte, O.; Bonneil, E.; Thibault, P.; et al. The exon junction complex controls the splicing of MAPK and other long intron-containing transcripts in drosophila. Cell 2010, 143, 251-262.

66. Roignant, J.Y.; Treisman, J.E. Exon junction complex subunits are required to splice drosophila map kinase, a large heterochromatic gene. Cell 2010, 143, 238-250.

67. Ishigaki, Y.; Nakamura, Y.; Tatsuno, T.; Hashimoto, M.; Shimasaki, T.; Iwabuchi, K.; Tomosugi, N. Depletion of RNA-binding protein RBM8A (Y14) causes cell cycle deficiency and apoptosis in human cells. Exp. Biol. Med. 2013, 238, 889-897.

68. Azzalin, C.M.; Lingner, J. The human RNA surveillance factor Upf1 is required for S phase progression and genome stability. Curr. Biol. 2006, 16, 433-439.

69. Rehwinkel, J.; Letunic, I.; Raes, J.; Bork, P.; Izaurralde, E. Nonsense-mediated mRNA decay factors act in concert to regulate common mRNA targets. RNA 2005, 11, 1530-1544.

70. Ishigaki, Y.; Nakamura, Y.; Tatsuno, T.; Hashimoto, M.; Iwabuchi, K.; Tomosugi, N. RNA-binding protein RBM8A (Y14) and Magoh localize to centrosome in human A549 cells. Histochem. Cell Biol. 2014, 141, 101-109.

71. Popp, M.W.; Maquat, L.E. Attenuation of nonsense-mediated mRNA decay facilitates the response to chemotherapeutics. Nat. Commun. 2015, doi:10.1038/ncomms 7632.

72. Jia, J.; Furlan, A.; Gonzalez-Hilarion, S.; Leroy, C.; Gruenert, D.C.; Tulasne, D.; Lejeune, F. Caspases shutdown nonsense-mediated mRNA decay during apoptosis. Cell Death Differ. 2015, doi:10.1038/cdd.2015.18.

73. Loffler, H.; Lukas, J.; Bartek, J.; Kramer, A. Structure meets function-Centrosomes, genome maintenance and the DNA damage response. Exp. Cell Res. 2006, 312, 2633-2640.

74. Albers, C.A.; Paul, D.S.; Schulze, H.; Freson, K.; Stephens, J.C.; Smethurst, P.A.; Jolley, J.D.; Cvejic, A.; Kostadima, M.; Bertone, P.; et al. Compound inheritance of a low-frequency regulatory snp and a rare null mutation in exon-junction complex subunit RBM8A causes tar syndrome. Nat. Genet. 2012, doi:10.1038/ng.1083.

75. Klopocki, E.; Schulze, H.; Strauss, G.; Ott, C.E.; Hall, J.; Trotier, F.; Fleischhauer, S.; Greenhalgh, L.; Newbury-Ecob, R.A.; Neumann, L.M.; et al. Complex inheritance pattern resembling autosomal recessive inheritance involving a microdeletion in thrombocytopenia-absent radius syndrome. Am. J. Hum. Genet. 2007, 80, 232-240.

76. Weischenfeldt, J.; Damgaard, I.; Bryder, D.; Theilgaard-Monch, K.; Thoren, L.A.; Nielsen, F.C.; Jacobsen, S.E.; Nerlov, C.; Porse, B.T. NMD is essential for hematopoietic stem and progenitor cells and for eliminating by-products of programmed DNA rearrangements. Genes Dev. 2008, 22, 1381-1396. 
77. Brunetti-Pierri, N.; Berg, J.S.; Scaglia, F.; Belmont, J.; Bacino, C.A.; Sahoo, T.; Lalani, S.R.; Graham, B.; Lee, B.; Shinawi, M.; et al. Recurrent reciprocal 1q21.1 deletions and duplications associated with microcephaly or macrocephaly and developmental and behavioral abnormalities. Nat. Genet. 2008, 40, 1466-1471.

78. Skorka, A.; Bielicka-Cymermann, J.; Gieruszczak-Bialek, D.; Korniszewski, L. Thrombocytopenia-absent radius (TAR) syndrome: A case with agenesis of corpus callosum, hypoplasia of cerebellar vermis and horseshoe kidney. Genet. Couns. 2005, 16, 377-382.

79. Singh, K.K.; Wachsmuth, L.; Kulozik, A.E.; Gehring, N.H. Two mammalian Magoh genes contribute to exon junction complex composition and nonsense-mediated decay. RNA Biol. 2013, 10, 1291-1298.

80. Mefford, H.C.; Sharp, A.J.; Baker, C.; Itsara, A.; Jiang, Z.; Buysse, K.; Huang, S.; Maloney, V.K.; Crolla, J.A.; Baralle, D.; et al. Recurrent rearrangements of chromosome 1q21.1 and variable pediatric phenotypes. N. Engl. J. Med. 2008, 359, 1685-1699.

81. Brahms, H.; Raymackers, J.; Union, A.; de Keyser, F.; Meheus, L.; Luhrmann, R. The C-terminal RG dipeptide repeats of the spliceosomal Sm proteins D1 and D3 contain symmetrical dimethylarginines, which form a major B-cell epitope for anti-Sm autoantibodies. J. Biol. Chem. 2000, 275, 17122-17129.

82. Mahler, M.; Fritzler, M.J.; Bluthner, M. Identification of a SMD3 epitope with a single symmetrical dimethylation of an arginine residue as a specific target of a subpopulation of anti-Sm antibodies. Arthritis Res. Ther. 2005, 7, R19-R29.

83. Brahms, H.; Meheus, L.; de Brabandere, V.; Fischer, U.; Luhrmann, R. Symmetrical dimethylation of arginine residues in spliceosomal Sm protein B/B' and the Sm-like protein LSM4, and their interaction with the SMN protein. RNA 2001, 7, 1531-1542.

84. Ma, X.M.; Yoon, S.O.; Richardson, C.J.; Julich, K.; Blenis, J. Skar links pre-mRNA splicing to mTOR/S6K1-mediated enhanced translation efficiency of spliced mRNAs. Cell 2008, 133, 303-313.

85. Gardner, L.B. Hypoxic inhibition of nonsense-mediated RNA decay regulates gene expression and the integrated stress response. Mol. Cell. Biol. 2008, 28, 3729-3741.

86. Oh, N.; Kim, K.M.; Choe, J.; Kim, Y.K. Pioneer round of translation mediated by nuclear cap-binding proteins CBP80/20 occurs during prolonged hypoxia. FEBS Lett. 2007, 581, 5158-5164.

87. Azzalin, C.M.; Reichenbach, P.; Khoriauli, L.; Giulotto, E.; Lingner, J. Telomeric repeat containing RNA and RNA surveillance factors at mammalian chromosome ends. Science 2007, 318, 798-801.

88. Chichinadze, K.; Lazarashvili, A.; Tkemaladze, J. RNA in centrosomes: Structure and possible functions. Protoplasma 2013, 250, 397-405.

89. Karam, R.; Wengrod, J.; Gardner, L.B.; Wilkinson, M.F. Regulation of nonsense-mediated mRNA decay: Implications for physiology and disease. Biochim. Biophys. Acta 2013, 1829, 624-633.

90. Miller, J.N.; Pearce, D.A. Nonsense-mediated decay in genetic disease: Friend or foe? Mutat. Res. Rev. Mutat. Res. 2014, 762, 52-64.

(C) 2015 by the authors; licensee MDPI, Basel, Switzerland. This article is an open access article distributed under the terms and conditions of the Creative Commons Attribution license (http://creativecommons.org/licenses/by/4.0/). 